\title{
THE MOBILE PRODUCTION OF PREFAB WOOD HOUSES
}

\author{
Prof. Dr. rer.nat. Leonid Lunin(1)Prof. Dr.-Ing. A. Bulgakow(1), \\ Prof. Dr. Yuri Panibratov(2), \\ Prof. Dr.-Ing. T. Bock(3), Dipl.-Ing. M. Kuehne(3) \\ (1)University of Southern Russia \\ (2)University of Saint Petersburg, Russia \\ (3)Technical University Munich, Germany
}

\begin{abstract}
The mobile automated production line for the manufacturing of prefab wood houses permits to organize the output of required quality products in a distance from industrial centers without engineering operational bases and high-skilled staff. It is capable to meet the requirements of various designs, to maintain the high effectiveness and reduce different forms of expanses.
\end{abstract}

KEYWORDS: mobile production, wood house, robotic, automation.

\section{INTRODUCTION}

The wooden constructions for the majority of Russian territories are the most acceptable and cost-effective type of housing erection. This is due to enormous reserves of wood, severe climatic conditions that are typical for Siberia and the Far North, and great difficulties in delivering the construction materials and structures to the construction site. As standards in housing quality increase, traditional woodwork methods in distant rural areas do not meet the up-to-day requirements. Indeed, there are no possibilities to organize there an industrial enterprise and to process construction materials. The low level of housing conditions in towns and countryside has led to a decreasing of population and labour turnover in the regions strategically important for the state. One of the main problems is the absence of highways necessary for organizing continuous cargo traffic and corresponding infrastructure, which would require more than one decade to be created. During the summer period rivers tend to be the main transport ways by which ready-products are delivered on board of cargo barges to many districts of Russia, and there is a possibility to use the load carrying capacity. The modern development of automatic control means make it possible to install them on board of river vessels and to create mobile automatic control algorithm for wood-working and making structural members of prefab houses of the quality required just at the construction site. And it is the way-out to avoid transport extra expenses which make much more expansive any construction project under the similar conditions as well as to eliminate the problem of deficit in high-skilled staff to maintain the lines, as there is a tendency of personnel lack in the sites. The above lines could be used during winter time if there are orders placed corresponding to their capacity, what could make a substantial increase in the rate of use of basic reserves and efficiency of the operation.

Civil engineering automation process, the manufacturing of ready-products in the departments and their erection at the building sites is known to contribute to the reformation of construction sites into assembling lines. Hence, the labour-intensive manual building procedures are reducing, given way to the erection of readyproduct.

The idea consists in developing and placing the readjustable operational line members of woodworking and manufacturing prefabricated wood houses on board of river barge as well as in coordinating and synchronizing its operation with the help of automatic control system and hence, in creating the mobile automatically operated manufacturing line.

\section{THEORETICAL AND EXPERIMENTAL RESEARCHES}

In order to develop the mobile automatically operated manufacturing line for prefab wood houses production, carrying platform is necessary which has the sufficient surface area to set up all the engineering sections of woodworking, pattern cutting and assembling of wall and infill panels. The freight river barges totally meet these requirements. The production line for prefab wood houses being placed on board of the 
above vessels should supply the automatic manufacture by members of production in different consignments, the product cost value and the mobile line capacity approximating to ones in up-to-day mass output, while making the members at the same range. The quality of houses being erected in such manner meets all modern standards on comfort, reliability, cost-

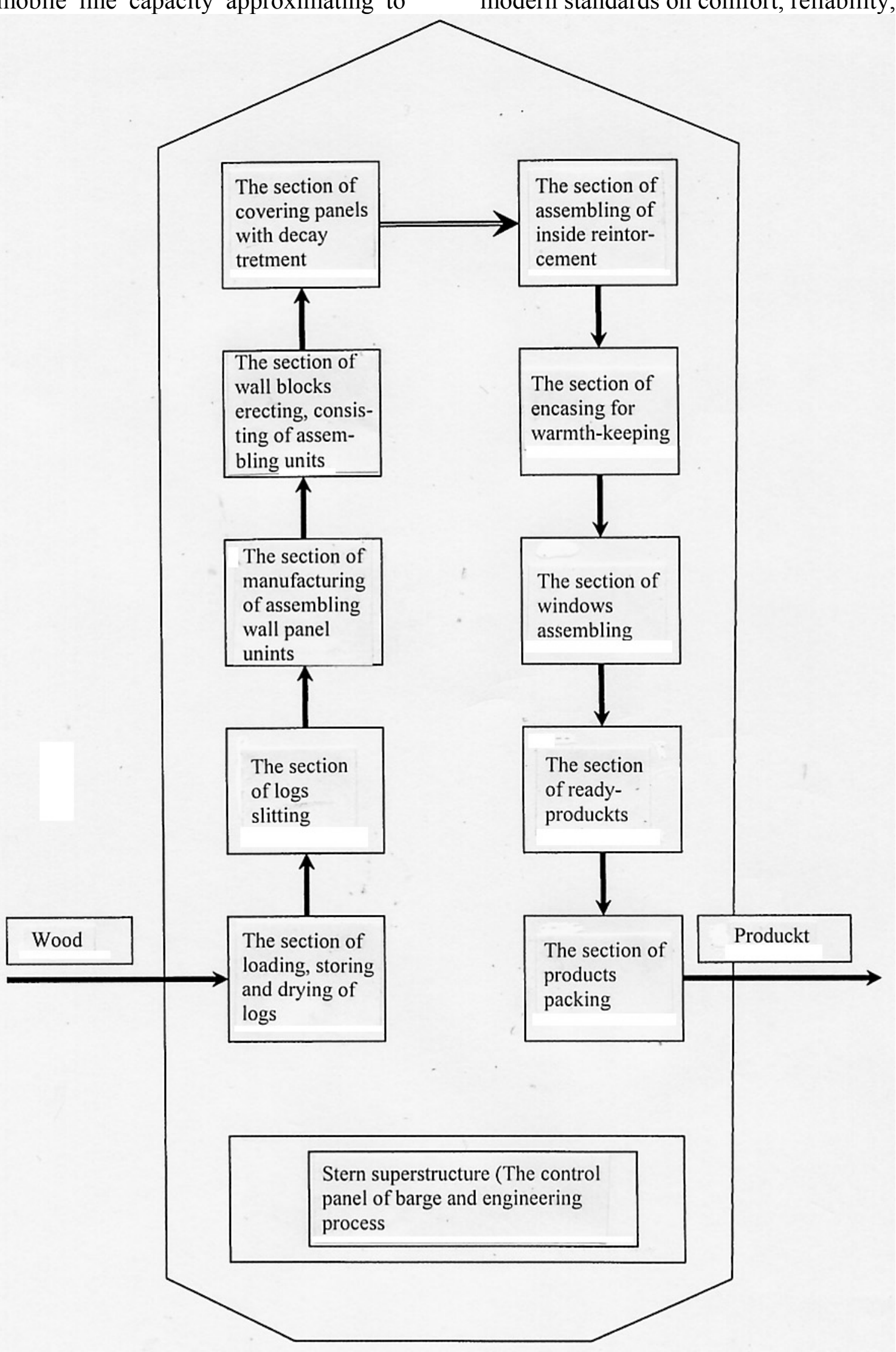

Fig.1 


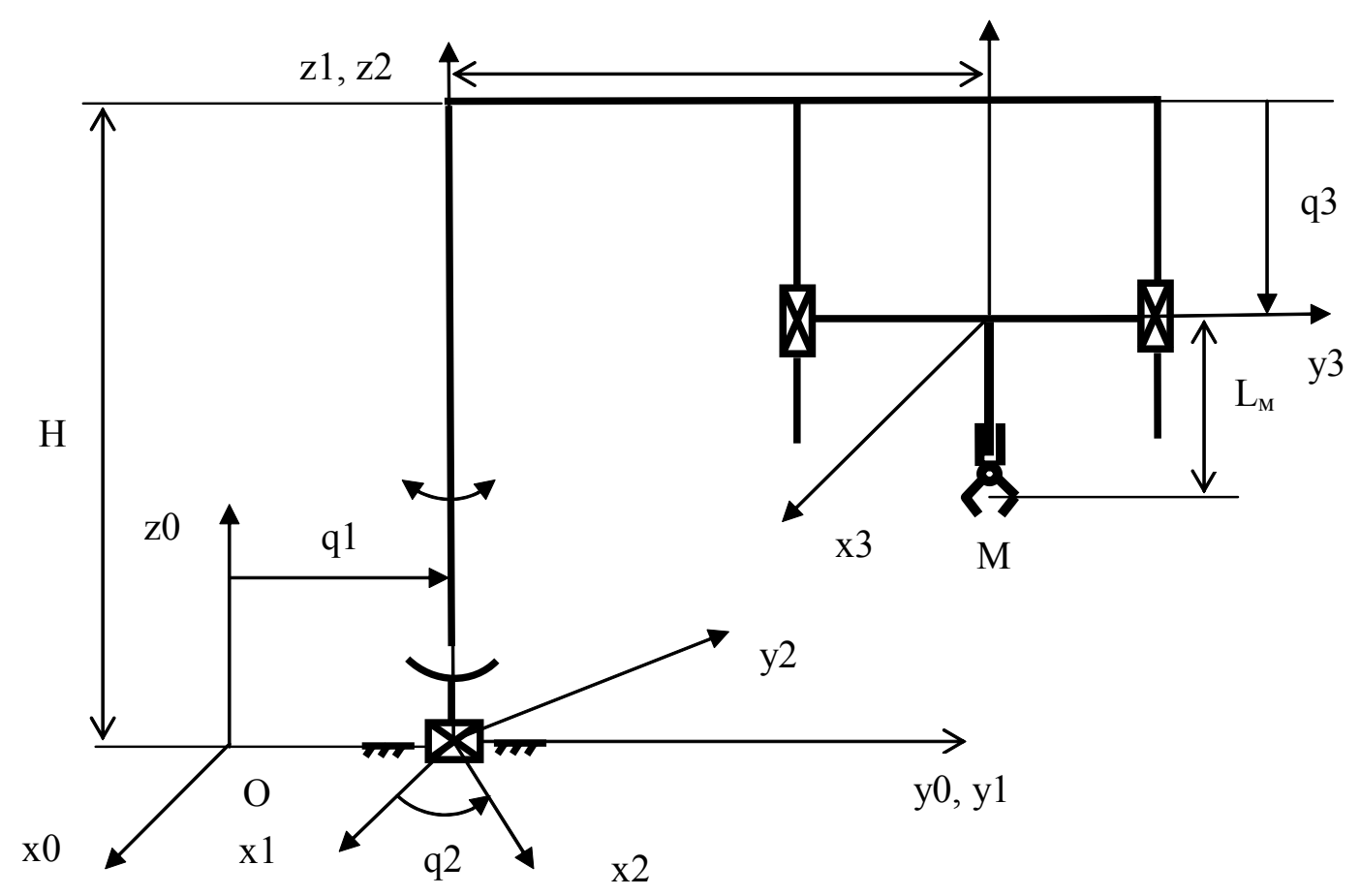

Fig.2

effectiveness, longevity and environmental safety.

The above engineering approach to creation of the mobile line for prefab wood houses production takes into consideration the dynamics of each technological section. The complete line is operated by the main control system, and it can react on the personal consumer's inquiries without the equipment being readjusted by hand. The basic criteria of the departments' arrangement design, sections and equipment are useful floor space on the deck and in holds of the vessel; the continuity of operational process; the opportunity to alter the sizes of sections and departments, setting up additional partitions between the operational sites or changing the equipment position.

The result of the operational process analyses of wood working has led to ten basic sections being formed, which are placed on the deck and partially in holds of the vessel. These are the sections of: loading, storing and drying of the materials in use; logs slitting; manufacturing of assembling units of wall panels; erecting wall blocks of assembling units; covering the wall blocks with antidecay treatment; placing inside reinforcement; incasing for warmth-keeping; installing windows; packing and storing of ready-products.

The stern superstructure or barge steer panel is not a comprehensive part of the arrangement sections design. Under another conditions it may be absent. But taking into account the abovementioned design the production control panel should be logically set at the same place where the steer system of the vessel is placed. The diagram of placing the sections on the vessel deck is shown in fig. 1 .

The control system of the line has three-level structure. The first level controls sections and intersectional processes. The operation control inside the sections is carried out on the second level. It is the control of robots drives and operational equipment that is carried out on the third level. For the wall panels being installed, the robot with six states of mobility is used: four receiprocant and two rotational. At the present design there is excess quantity of regional states of mobility. The redundancy is introduced in order to obtain more efficient design of manipulator, as the line is placed on board of a river barge and there are strict clearance limits. The design scheme of the manipulator is shown in fig. 2.

The equations of its members' motion are the following:

$$
\begin{aligned}
& \left(m_{1}+m_{2}+m_{0}\right) \cdot \mathbb{Q}=Q_{1} ; \\
& \left(m_{2}+m_{0}\right) \cdot d=Q_{2} ; \\
& {\left[I_{Z} \cdot\left(1+\sin ^{2} q_{2}\right)+I_{X} \cdot \cos ^{2} q_{2}+m_{0} L_{M}^{2}\right] \cdot q_{3}=} \\
& =Q_{3}-m_{0} g \cdot L_{M} \cdot \cos q_{2} .
\end{aligned}
$$

where $m_{0}-m_{2}$ - stated masses of members; 
$q_{1}-q_{6}$ - generalized coordinates;

$I_{Z}, I_{X}, L_{M}$ - design ratings of the manipulator.

The industrial system PROFIBUS links all the sections of the flexible operation line. The control of technological process, a great deal of different calculations with the use of a few personal computers, the exchange of data and information between various terminals or network users, allocated storage of information on different storage medium are effected with the help of the PROFIBUS system. The PROFIBUS standard uses two main types of connection channels: DP and PA. PROFIBUSDP sustains the data transmission at high speed from 9,6 to $12000 \mathrm{Kbps}$, using RS-485. The transmissions data region is asynchronic. PROFIBUS-PA has the synchronic mode of data transmission at speed $31,25 \mathrm{Kbps}$. Besides the informational signal, power supply of operated device is passed along the PA channel. PA channel is used for the devices operating in explosive and hostile conditions. PROFIBUS system gives the opportunity to establish the control of the line in question at new different level. The structure of PROFIBUS-DP cable is shown in fig.7. The transmission data mode is carried out at EIA RS-485 standard. The conductors of cable segments are closed on the both ends at resistance $390 \mathrm{Om}$. The mode of transmission is asynchronic semi-duplex. The data are transmitted inside the 11-digit frame, in so-called NRZ-code (Not Return to Zero). Bits are not changed while transmission. When logical " 1 " is transmitted in conductor B, " 0 " is in conductor A. Voltage level at $5 \mathrm{~V}$ corresponds to logical "1", while Zero - $0 \mathrm{~V}$.

Due to resistances at which cable wires are closed, safe potential of rest is set on the wires at the moment, when there is no exchange of information between network participants. Almost all PROFIBUS connectors carry the cable resistance. Switchers activate them.

\section{STATEMENT}

The concept of mobile automated production line that comprises the placing of the readjustable engineering sections on wood-working, and manufacturing the prefab wood houses on board of river barge and maintaining the process of coordination and synchronization with the help of automatic control system can be put into use in practice.The selection of kinematical robots structures which are the integral part of engineering line, taking into account the planning of sections, compositions, clearance limits and arrangement of engineering equipment, geometry of subject of manipulating (dimensions, shape), displacement types of the subject of manipulating is substantiate.

While designing the mobile automated production line on wood houses manufacture, industrial system PROFIBUS is used. It maintains the control algorithms in all the line modules and allows operating without complementary adjustment when new components are added to the line. PROFIBUS system uses link channel in the form of serial field cable. The cable is a screened pair, encased in sheath.

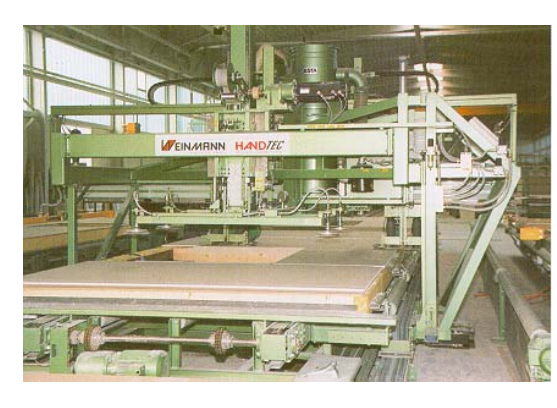

Multifunctional wood panel production unit

Ref.: T. Bock, TU Munich, Germany 